\title{
FEMALE BODY CONCERNS IN HEALTH RESEARCH: A FEMINIST PSYCHOLOGICAL PERSPECTIVE
}

\author{
Tissy Mariam Thomas*
}

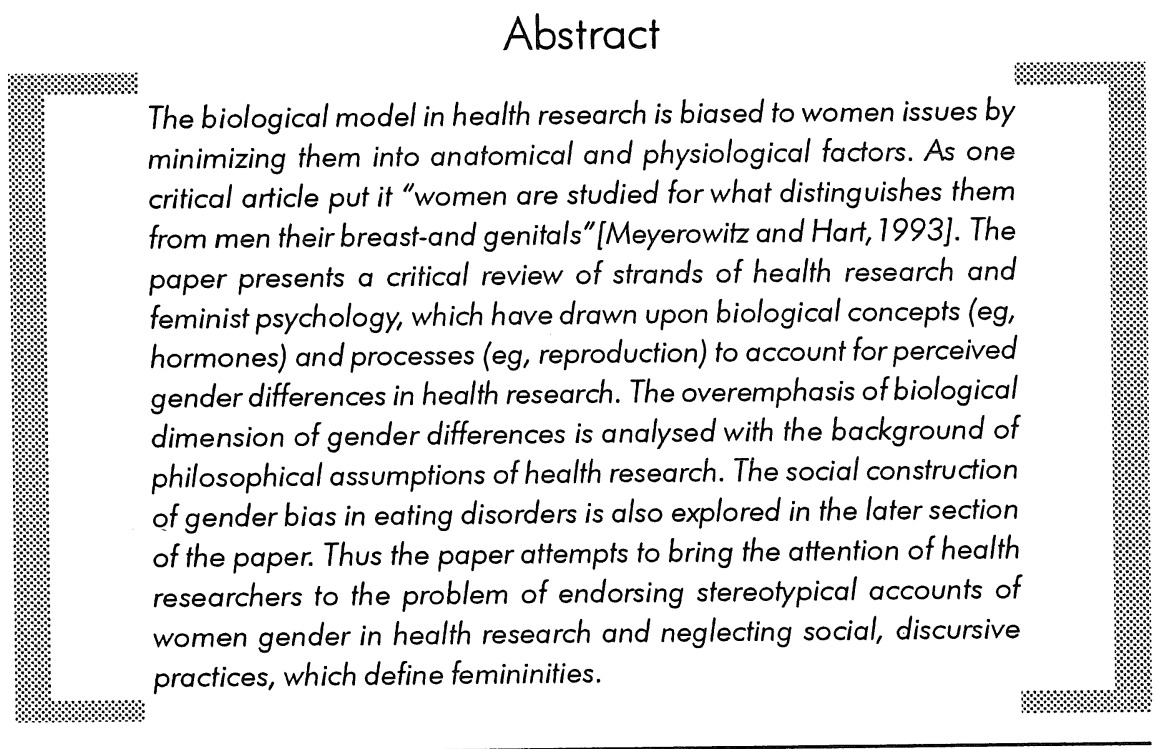

* Lecturer, Dept. of Postgraduate Studies in Psychology, Christ College, Bangalore e-mail: tissymariam@christcollege.edu 
'Power is a key dimension in the cultural construction of medical knowledge. Medical systems frequently reproduce inequalities and hierarchies in a society by naturalizing and normalizing inequalities through facts and images about the body, (Larme, 1998 cited from Ostlin, 2006).

The history of health research has been sidelined women's health concerns similar to any other areas of biases and discrimination against women for years. Across cultures, the inequities in the gender equations of power stress the significance of a feminist rereading of power into health research and the unequal power and status attributed to female and male body images. The growing strength of the women's movement in the 1960s and 1970s challenged the 'medicalization' of women's bodies and the medical construction of woman's health needs as distinct from women's own experiences and priorities.

Feminism as a critical discipline has made inroads into many mainstream disciplines, including Psychology, often radically questioning their working assumption about femininity, female identity, female sexuality, etc (Davar, 1999). Feminist focus in Psychology has questioned the universal models of psychological functioning, the research methods, assessment techniques and the male bias in psychological theories, which are responsible for contributing to a partial and distorted understanding of women's issues (Bharat, 2001).

\section{Biological Model for Female Body Concerns: The History}

During the 19th and early 20th century, differences in health between men and women have been analysed using a biological/genetic model developed within Western medicine. This model emphasized that biological makeup in terms of reproductive functions and physiology, and more recently hormones and genes, were of primary importance for understanding health differences between women and men. Less than 100 years ago, every female health problem would often be reduced, directly or indirectly, to a gynaecological disorder. Problems with the uterus and other reproductive organs were perceived to influence every other organ. Migraine headaches, heart failure, eye problems were seen as functional disturbances in the reproductive organs. Women's reproductive biology is linked with mental health, illustrated by the use of the term 'hysteria' where mental disturbance is linked to the uterus. The reduction of women to their reproductive functions led to the overemphasis of medical treatment of women. 


\section{Health as "Normal" for Women: Another Face of Oppression?}

Women were characterized in the medical literature by hormonal cyclical instability and constitutional weakness. III health was seen as a more normal condition for women while good health was seen as the hallmark of the normal male body (Ostlin, 2007). The perception of women as biologically weaker, delicate and more susceptible to being invalid, discouraged women from engaging in various activities in society, especially from entering higher education on the basis of their 'fragile' constitution and 'delicate' nerves. There was a belief that since women's energy was needed for reproduction, they remained inferior to men in terms of intellect and creativity which was supported by the scientific community in terms of evolutionary theories to prove that women's subordinate position was biologically determined. Thus the biological differences between women and men have 'naturally' led to and justified different and unequal social status or rights for women (Ostlin, 2007).

\section{The Social Dimension of Female Body Concerns}

During the 1950s and 1960s it became more and more clear that biological/ genetic explanatory models could not provide a complete framework for analysing causes of differences in health between women and men. Women's health researchers called for more attention in health research to explanatory factors related to women's lives and work. In most societies there are not just gender differences but inequalities inherent in the social definitions of femaleness and maleness in terms of responsibilities, distribution of power, income and wealth and in political sphere as well. These inequalities often prevent women from getting the right kind of health care for their "unidentified" or "undiagnosed" health issues.

Studies have shown that many of the health problems women face are not related in any direct way to their specific biological characteristics. Depression for instance, is more commonly reported by women than by men yet there is no evidence that women are constitutionally more susceptible to these problems (Busfield, 1996). Moreover, a considerable amount of the illness women experience can be traced back to the gender discrimination that shapes many aspects of their existence (Annandale and Hunt, 2000). As well as affecting women's physical and mental health, gender inequalities also affect their use of health care and the quality of the services they receive. When they do get access to care there is evidence that women may receive treatment which is technically inferior to that received by men and may also be delivered in less respectful ways (WHO 1998; Petticrew, McKee \& Jones 1993). 
The idea of gender as a determinant of the health of women and men appears a century and a half later in research of the late 1980s and the 1990s (Macintyre 1996; Sen et al 2002 cited from Kwaak and Dasgupta, 2006). It emerged that men and women are a product of not only their own biology, but also their social experiences in a stratified society and the gendered roles that they enact (Bird and Rieker 1999). When attempting to understand health related differences between women and men, it is important to analyse the complex ways in which biology and social factors interact since social determinants exacerbate biological vulnerabilities (Sen et al 2002). Knowledge of the body, health and illness is culturally constructed (Sen et al 2002), and this is most evident in the case of medical knowledge about the health needs of women gender (Kwaak and Dasgupta, 2006). Social construction of female body concern needs to be directed thoroughly with appropriate qualitative descriptive research methods in order to incorporate many of the unique physical and mental health issues of women.

The women's movement also questioned the fallacy that males, as doctors, knew better or more about women's bodies than women. This bias perceived female health problems from male eyes, without appreciation of the agonies involved in being a woman in a tradition bound, male dominated society. Taylor (2001) commented that the raising number of women in the medical profession have changed what was once a very clear physician's role characterized by the dominance and authority (Goldstein et al, 1987).

\section{Feminist Criticisms to Philosophy of Science in Health Research}

The mainstream philosophy of medical research encourages the logical assumptions of reductionism, determinism, individualism and the sexist language in understanding the health needs of women.

Reductionism reduces the complexity of social phenomena to its key components and underlying mechanisms. But it misses the context in which those phenomena exist. By reducing women to their body components and studying them one by one, the existing research never takes the cultural, institutional, historical, legal and political construction of womanhood. The 'missing link' in these types of researches is the women and their unique experiences. This approach clearly follows the overemphasis of male norms in understanding the real problems of women. The assumption of determinism already set the pre-existing factors of what leads to what outcomes. Social behaviour is explained in terms of antecedent- consequent interaction so that any event has a predictable form. This kind of logic dehumanizes 
women and deprives them of any kind of autonomous action, particularly the capacity to resist oppressive forces in their individual lives and individualistic or collective responses towards them. The historical dimensions of women's changing roles in society and the reciprocal causality of events/variables do not acquire a place in the health research as research is more interested to establish the predetermined relation between some variables.

The individualistic perspective of science narrows down the socialization process and the social experiences of women, which leads to missing "the big picture". Critics have argued that the naturalization (hence inevitability) of social roles and health-related behaviours linked to those roles in research and policy led to 'blame' the victims and center the ultimate responsibility for a behavioural change of lifestyle as solution to women rather than on policy change at the societal level.

The research language is criticized for the clear partiality of male domination. The ideology of health research is also questioned as the values, problems and experience follows the masculine frame of reference. As the women gender is historically "conditioned" to accept and lead their life under social oppression, the male logic and ideology had never been able to figure out the health experiences of women. This explains the fallacy of conclusions made by mainstream health research in terms of female body construction.

\section{Eating Disorders: Gender Bias in Female Body Image Concerns}

The women are always affected by the notions of beauty, "figure" and physical attractiveness historically. In this context, the so-called eating disorders are being analysed critically from the feminist psychological point of view in terms its symptoms, causes and treatment methods. Figures show that eating disorders have a social origin. Media, ethnicity, social class and family environment are also causes of body dissatisfaction. Heightened body dissatisfaction explains distorted body size estimation and a perception that the body is larger than it really is.

It points out the fact that the present feminine state of health is maintained by emphasizing the biological processes and hormonal consequences. This is actually a contradictory point of view. In one hand, the health concerns are explained in terms of biological dimension and a deviation from such a standard is considered as "disorder" wherein its symptoms, causes and treatment methods are closely products of the specific cultural gender stereotypes. The abnormal eating pattern of 
women in pursuit of thinness has to be considered as a growing social problem and a public health threat. Attempts should be made to trace the societal roots of these disorders.

\section{In search of a 'perfect figure': Barbie Beauty of Anorexia Nervosa}

Taylor (2006) puts forth from Facts of Life (Nov. 2002) that in pursuit of the elusive perfect body, numerous women chronically restrict their diet and engage in other weight-loss efforts such as laxative use, cigarette smoking and chronic use of pills. Females between the age of 15 and 24 are most likely to be affected by eating disorders and as many as $20 \%$ of people with anorexia nervosa will die prematurely (Center for the Advancement of Health, 2002). Anorexia Nervosa is an obsessive disorder amounting to self-starvation, in which an individual diets and exercises to the point that body weight, is grossly below optimum level, threatening health and potentially leading to death. $78 \%$ of women report that they are trying to lose or at least not gain weight (Centers of Disease Control \& Prevention, 2000). Researches have been conducted for the physiological explanation of this disorder. Despite the traces of genetic contribution, chromosomal abnormality, high blood pressure, depression, low self-esteem, much research look at the role of social factors such as media, ethnicity, social class and the family environment in causing body dissatisfaction. Research has also explored the role of psychological factors such as beliefs, mother-daughter relationship and role of control that may translate the social factors into actual body dissatisfaction (Ogden, 2000).

Many health psychologists have criticized the media and the products they popularize for perpetuating false images of feminine beauty (J.K. Thompson \& Heinberg, 1999). The Barbie doll has come under the particular criticism because researchers believe that its widespread popularity with young girls may contribute to excessive dieting and the development of eating disorders on order to reach the unattainable standards of beauty (her bust by 5 inches, her neck length by more than 3 inches, her height by more than 2 feet and her waist by 6 inches). Media is successful in promoting that thinness is not only the desired norm but also the actual norm (Ogden, 2000).

\section{Bulimia, the Other Side of 'Thinness'}

Bulimia is characterized by alternating cycles of binge eating and purging through such techniques as vomiting, laxative abuse, extreme dieting or fasting, and drug or alcohol abuse. Girls and women with bulimia are characterized by an excessive 
concern with body and weight; a preoccupation with dieting; a history of depression, psychopathology, and alcohol or drug abuse; and difficulties with managing work and social settings (Spitzer et al., 1993). Another study reveals that families that place a high value on thinness and appearance are more likely to produce bulimic daughters (Boskind- White \& White, 1983).

The media pictures fat actresses as either evil or unhappy, not as normal women (Ogden, 2000). One study of women in college found that their bulimia worsened in response to stress or to any experience that led to a feeling of being unattractive, overweight, or ineffectual (Striegel-Moore et al.,1989). Overweight young women are exposed to gendered discrimination socially which probably occurs in many arenas, based on the societal norms for female bodies in the society.

Although men are more likely than women to store fat on their upper bodies, and are therefore more at risk if obese, women are more concerned about weight than men and most treatment studies examine women (Ogden, 2000). Body image concerns about a partner's reactions represent psychosocial vulnerabilities more in the case of women than men, especially when there has been disfiguring surgery, as in the case of breast cancer (Spencer et al., 1999).

Classifying abnormal eating pattern as a disorder and treating them based on individualized medication and therapy, actually problematise the medical concept of health in general. The social processes involved in the construction and search for female body image and perfect body figure is very much away from the medical explanation of eating disorders.

\section{Body vs. body: the Issue of Coping Strategies in Females}

The biologically oriented health research on women suggests a lot of individual coping strategies (which again concentrates on body) to women order to deal with their health related problems. One among them is exercise. Because of the benefits of $30 \mathrm{mts}$ aerobic exercise a day on mood and self-esteem (McAuley, 1997), exercise has been used as a treatment for depression (Herman et al, 2002) and for symptoms of menopause (Slaven \& Lee, 1997 cited in Taylor, 2006). A study on depression show that once treatment was discontinued, those who continued to exercise were less likely to become depressed again when compared with those who had been on the drug treatment (Babyak et al, 2000). This indicates that lifestyles of women may not afford opportunities for regular exercise (Cody \& Lee, 1999). Even though physical activity is more common among women than men (Lee \& King, 2003), 
women report significant barriers to getting exercise, including care giving responsibilities and concomitant lack of energy (King et al, 2000). Studies also show that from an early age, boys get more exercise than girls (Sallis et al, 1993). This kind of coping approach actually attributes women's problems on the shoulders of women again. Thereby the medical profession will be able to wash their hands cleanly and to take a safer position of not responsible on the social aspects of the issues. It is argued that the roots of health research on women- both causes and consequences- centers around naturalizing the female body/ biological processes which has to be relooked as the relative existence of womanhood is socially determined.

\section{Conclusion}

The paper has implications to the fields of health psychology, medical research, research methods in social sciences, feminist psychology and social psychology. To understand health related differences between women and men, an analysis has to move beyond the health sector to look at the complex ways in which biology and social factors interact. Critical reflection on feminist psychology perspectives on health research provides a platform to incorporate the important variable of social interaction while approaching female body concerns. Without a systematic investigation of women's body concerns and their particular risk factors, as well as changes in both over the life span, women will simply be treated more poorly than men for the same diseases (Taylor, 2006).

\section{References:}

- Bharat, S. (2001) On the Periphery: The Psychology of Gender. In Pandey, J (2001) Psychology in India Revisited Vol. 2. New Delhi: Sage Publications

- Brannon, L. \& Feist, J (2000) Health Psychology. Australia: Brooks/Cole

- Davar, B.V. (1999). Moral Development and Mental Distress: A Feminist Proposal. In T.S. Saraswathi (Ed). Culture, Socialization and Human Development. New Delhi: Sage.

- Doyal, L. (1995). Gender Equity and Public Health In Europe - A Discussion Document. Website: http://www.eurohealth.ie/gender/section3.htm

- Gough, B \& Mc Fadden, M. (2001). Critical Social Psychology: An Introduction. New York: Palgrave

- Hammarstrom A.(n.d.). Medicine has much to learn from gender studies. Website: hHtp:// www.ncbi.nlm.nih.gov/entrez/query

- Kumar, U (2001) Indian Women and Work: A Paradigm for Research. Dalal, A.K.\& Misra, G (Ed) New Directions in Indian Psychology. Vol. 1: Social Psychology. New Delhi: Sage Publications 
- Kwaak, A and Dasgupta, J. (2006). Introduction: Gender and health. In Kwaak, A and Wegelin-Schuringa, M (Eds) Gender and Health: Policy and Practice A Global Sourcebook United Kingdom: Oxfam Publishing

- McGhee, P.(2001). Thinking Psychologically. New York: Palgrave.

- Östlin, P (2006) Gender in Health Research - Past, Present and Future

- Sen, G., A. George and P. Östlin (eds) (2002). Engendering international health: the challenge of equity. Cambridge: MA, MIT Press.

- Taylor, S. E. (2006). Health Psychology. 6"t Ed. Boston: Mc Graw Hill

- hitp://www.who.int/gender/en/ 